\title{
Asymptomatic bronchial hyperresponsiveness to exercise in childhood and the development of asthma related symptoms in young adulthood: the Odense Schoolchild Study
}

Finn Rasmussen, Jess Lambrechtsen, Hans Christian Siersted, Henrik Steen Hansen, Niels-Christian Hansen

\begin{abstract}
Background-Exercise testing may be of value in identifying a group of children at high risk of subsequently developing respiratory symptoms. As few longitudinal studies have investigated this issue, the bronchial hyperresponsiveness to exercise in asymptomatic children was evaluated as a risk factor for developing asthma related symptoms in young adulthood. Methods-A community based sample of 1369 schoolchildren, first investigated in 1985 at a mean age of 9.7 years, was followed up after a mean of 10.5 years. Nine hundred and twenty children (67\%) were asymptomatic in childhood and 777 $(84.9 \%)$ of these were re-investigated at follow up. At the first examination a maximum progressive exercise test on a bicycle ergometer was used to induce airway narrowing. The forced expiratory volume in one second $\left(\mathrm{FEV}_{1}\right)$ after exercise was considered abnormal if the percentage fall in $\mathrm{FEV}_{1}$ was more than $5 \%$ of the highest fall in the reference subjects characterised by having no previous history of asthma or asthma related symptoms. The threshold for a positive test was $8.6 \%$ of pre-exercise FEV $_{1}$.
\end{abstract}

Results-One hundred and three subjects $(13 \%)$ had wheeze within the last year at follow up and, of these, nine ( $9 \%$ ) had been hyperresponsive to exercise in 1985 . One hundred and seventy subjects (22\%) had non-infectious cough within the previous year, 11 of whom (6\%) had been hyperresponsive to exercise in 1985 . Multiple regression analysis showed that subjects with hyperresponsiveness to exercise had an increased risk of developing wheeze compared with subjects with a normal response to exercise when the fall in $\mathrm{FEV}_{1}$ after exercise was included as a variable (threshold odds ratio (OR) 2.3 (95\% CI 1.1 to 5.5)). The trend was not significant when exercise induced bronchospasm was included as a continuous variable (OR $1.02(95 \%$ CI 0.97 to 1.06$))$.

Conclusions-Asymptomatic children who are hyperresponsive to exercise are at increased risk of developing new symptoms related to wheezing but the predictive value of exercise testing for individuals is low.

(Thorax 1999;54:587-589)
Keywords: asthma; exercise testing; children; young adults; symptom development

Asymptomatic bronchial responsiveness seems to be a risk factor for the development of asthma ${ }^{12}$ but only a few studies have investigated whether the risk of new symptoms can be categorised according to exercise performance. In a cross sectional study Busquets et $a l^{3}$ concluded that the prevalence of asthma related symptoms and bronchial responsiveness to exercise had different meanings in a community survey. However, exercise induced bronchospasm can be measured before the onset of asthmatic symptoms ${ }^{4}$ and this could reflect a state of "latent asthma" in the airways.

The aim of this study was to investigate whether exercise induced bronchospasm in childhood could predict the development of new asthma related symptoms in later childhood and adolescence.

\section{Methods}

POPULATION

A cohort of 1369 schoolchildren in third grade participated in the initial study. The mean age was 9.7 years (range $8.4-11.4$ ). The details of the random population selection and examination have previously been published. ${ }^{5}$ Nine hundred and twenty children (67\%) were asymptomatic in childhood, 777 of whom $(84.9 \%)$ were re-investigated at follow up.

Parents gave informed consent for their children to participate in the baseline study and subjects gave informed consent before participating in the follow up study. The study was approved by the local research ethics committee and the Danish Data Surveillance Authority.

\section{EXERCISE TEST}

The exercise challenge test in childhood involved maximum progressive exercise on a bicycle ergometer with an increase in work load every third minute until exhaustion. ${ }^{6}$ Nose clips were not used. The heart rate was measured with a Polar Sport tester. The effort was accepted as maximal when the subject reached a heart rate of 185 beats $/ \mathrm{min}$. A McDermott bellows spirometer was used to measure forced expiratory volume in one second $\left(\mathrm{FEV}_{1}\right)$ before exercise and at 5 and 10 minutes after exercise. The European guidelines for spirometric testing were followed. ${ }^{7}$ 
Table 1 Symptom prevalence (\%) at follow up according to categories of exercise induced bronchospasm at inclusion in the study

\begin{tabular}{llll}
\hline Exercise induced fall in FEV ${ }_{1}(\%)$ & Asthma & Wheeze & Cough \\
\hline Rise $(<0 \%)$ & $16 / 282(5.7 \%)$ & $36 / 282(12.8 \%)$ & $58 / 282(20.6 \%)$ \\
$0-4.9 \%$ & $25 / 360(6.9 \%)$ & $43 / 360(11.9 \%)$ & $82 / 360(22.8 \%)$ \\
$5-8.5 \%$ & $8 / 100(8.0 \%)$ & $15 / 100(15.0 \%)$ & $19 / 100(19.0 \%)$ \\
$\geqslant 8.6 \%$ & $6 / 35(17.1 \%)$ & $9 / 35(25.7 \%)$ & $11 / 35(31.4 \%)$ \\
\hline
\end{tabular}

Table 2 Adjusted associations of risk factors and their 95\% confidence interval (95\% CI) with wheeze and cough. Hyperresponsiveness to exercise

\begin{tabular}{|c|c|c|}
\hline & Wheeze $(95 \%$ CI) & Cough $(95 \%$ CI) \\
\hline Exercise induced bronchospasm ${ }^{\star}\left(\geqslant 8.6 \%\right.$ fall in $\left.\mathrm{FEV}_{1}\right)$ & $2.3(1.1$ to 5.8$)$ & $1.4(0.6$ to 3.2$)$ \\
\hline Tobacco smoking ${ }^{\star}(\geqslant 1$ pack-year $)$ & $3.6(2.2$ to 5.7$)$ & $4.2(2.9$ to 6.1$)$ \\
\hline Allergic rhinitis at baseline ${ }^{\star}$ & $3.5(1.6$ to 7.7$)$ & $1.7(0.8$ to 3.6$)$ \\
\hline Asthma in the family ${ }^{\star}$ & $1.5(0.8$ to 3.0$)$ & $3.6(2.2$ to 5.7$)$ \\
\hline Sex $(\text { female })^{\star}$ & $1.6(0.9$ to 2.5$)$ & $1.3(0.9$ to 2.0$)$ \\
\hline
\end{tabular}

^Adjusted for all factors including baseline $\mathrm{FEV}_{1}$.

Lung function after the exercise test was expressed as the maximal fall in $\mathrm{FEV}_{1}$ as a percentage of the pre-exercise $\mathrm{FEV}_{1}$ measurement. The exercise test was considered abnormal if the percentage fall in $\mathrm{FEV}_{1}$ was more than 5\% of the highest fall in the reference subjects characterised by having no previous history of asthma or asthma related symptoms. ${ }^{1}$ The threshold for a positive test was $8.6 \%$.

QUESTIONNAIRE

All subjects who answered positively in 1985 to at least one of the questions on asthma or the presence of asthma related symptoms were excluded from the analysis. Asthma related symptoms were asked with reference to the previous one year period (see Appendix). The question: "Do you have hayfever?" was used to identify subjects with allergic rhinitis in 1985 . A history of asthma in the family was noted if at least one parent or one sibling had asthma. Subjects were labelled smokers if their estimated lifetime tobacco consumption exceeded one pack year. The pack year estimate was calculated by multiplying the tobacco consumption in grams per day divided by 20 with the duration of smoking in years.

DATA ANALYSIS

$\chi^{2}$ tests and $t$ tests were used to compare participants and non-participants. A multiple logistic regression model was applied with symptom status at follow up as the dependent variables. Two different symptom definitions were used as dependent variables - wheeze and non-infectious cough. The independent variables introduced into the model were bronchial hyperresponsiveness to exercise, sex, allergic rhinitis, tobacco smoking, $\mathrm{FEV}_{1} \%$ predicted, and history of asthma in the family. Two tailed tests were used with a $5 \%$ significance level. The analysis was performed using SPSS-PC+ 7.5.1 (SPSS Inc, Chicago, Illinois, USA).

\section{Results}

No statistically significant differences were found between participants and nonparticipants at follow up with respect to sex, age, birth weight, or the data measured in 1985 (prevalence of allergic rhinitis, physical fitness, height, weight, body mass index, $\mathrm{FEV}_{1}$ and FVC). Hyperresponsiveness to exercise in
1985 and the relation to the development of asthma related symptoms at follow up are shown in table 1 . One hundred and three subjects $(13 \%)$ had wheeze during the last year at follow up of whom nine $(9 \%)$ had been hyperresponsive to exercise. One hundred and seventy subjects $(22 \%)$ had non-infectious cough within the previous year, 11 of whom $(6 \%)$ had been hyperresponsive to exercise in 1985.

The results obtained by multiple regression are shown in table 2 . If hyperresponsiveness to exercise was included as a continuous variable in the model it was positively associated with both wheeze and cough 10 years later, but without reaching statistical significance (odds ratios (OR) 1.01 (95\% CI 0.97 to 1.06 ) and 1.01 (95\% CI 0.97 to 1.05 ), respectively.

\section{Discussion}

Previously symptom free children who were hyperresponsive to exercise had a greater risk of developing wheeze in early adulthood than asymptomatic children with a normal response to exercise. Exercise induced bronchospasm had only a weak association with cough and the main contributor to the development of cough was tobacco smoking.

Increased airway responsiveness to various stimuli is a feature of asthma ${ }^{9}$ and may be determined genetically. ${ }^{10}{ }^{11}$ Wheeze seems to be more closely associated with bronchial responsiveness than cough. ${ }^{312}$ Haby and coworkers showed that exercise induced bronchoconstriction could be measured before the onset of symptoms in childhood and the degree of responsiveness was positively associated with wheeze attacks during the previous year. ${ }^{4}$ The sensation of respiratory symptoms may have to exceed a certain "threshold" before respiratory discomfort develops. ${ }^{13}$ This may explain why hyperresponsiveness to exercise can be detected before asthma related symptoms are reported. However, the association is undoubtedly more complex as a large part of the population will experience wheeze without a demonstrably abnormal fall in $\mathrm{FEV}_{1}$ after exercise. ${ }^{14}$ This may be partly due to the high variability and low agreement between replicate exercise tests resulting from the high intrinsic variability in airway calibre, particularly in asthmatic subjects. ${ }^{15} 16$

The maximum progressive exercise test on a bicycle ergometer has mainly been used to measure physical fitness by an indirect measure of maximal oxygen uptake $(\mathrm{ml} / \mathrm{kg} / \mathrm{min})$ and it has been claimed to have some limitations for assessment of exercise induced bronchospasm. ${ }^{17}$ Physiologically there is no evidence that the mechanisms of exercise induced airway narrowing differ between a running test and a bicycle test ${ }^{81718}$ but, when the bicycle test is used to provoke airway narrowing, it has been claimed that bicycle testing seems to be a poorer stimulus than running in provoking an attack of asthma. It has also been claimed that the coefficients of variation between repeated tests vary more than in running tests,${ }^{17}$ and that the maximal degree of airway narrowing in subjects occurs at $60-85 \%$ 
of their predicted maximum oxygen consumption. Durations longer than this and expenditure of greater power are claimed to be associated with flattening or diminution of the response. Subsequent studies have not confirmed these observations. ${ }^{18-21}$ Furthermore, the cut off values obtained to indicate the $5 \%$ "most asthmatic" of the reference subjects for an abnormal test corresponded with previous findings in other studies, ${ }^{422}{ }^{23}$ so we think that our bronchoconstriction test can be used to assess the present research question.

In conclusion, we have shown that asymptomatic children who were hyperresponsive to exercise were at higher risk of developing asthma related symptoms as young adults than children without hyperresponsiveness to exercise. This suggests that abnormal airway changes may precede the onset of asthmatic symptoms. However, the exercise test has insufficient predictive value to be useful as a guide to individual prognosis.

\section{Appendix}

In 1985 subjects with asthma were identified by the question: "Have you ever had asthma, i.e. periods of wheeze and/or cough?" and asthma like symptoms by the questions, asked with reference to the previous one year period: "Do you have wheeze and/or cough at rest?", "Do you have wheeze and/or cough when you are exercising?", "Do you feel shortness of breath at night?", "Do you feel shortness of breath in the morning?", "Do you have wheeze and/or cough in foggy weather?" and "Do you have bronchitis, i.e. periodic cough during several days/weeks?".

At follow up, asthma was identified by an affirmative answer to the question: "Is it your doctor's opinion that you have asthma?". Asthma like symptoms were identified by the questions, asked with reference to the previous one year period: "Do you have attacks of breathing trouble with wheezing or whistling?", "Do you have trouble breathing at night?", "Do you have trouble breathing at all?" and "Have you had a period with cough lasting three or more days in succession?". Cough in relation to colds was only considered if lasting two weeks or more (additional questions asked: "Do you only cough in connection with colds?" and "For how long does the cough period usually last?"). ${ }^{24}$

The authors are indebted to Niels Hyldebrandt who encouraged them to start the study. The study was supported by the Danish Lung Association, The Danish Medical Research Council,
Odense University, The Hørslev Foundation, K A Rohde and his wife's Foundation, Else and Mogens Wedell-Wedellsborg Foundation, and CEO Jacob Madsen and his wife Olaga's Foundation.

1 Godfrey S, Bar YE. Exercise-induced asthma revisited. Respir Med 1993;87:331-44.

2 Jones A, Bowen M. Screening for childhood asthma using an exercise test. Br F Gen Pract 1994;44:127-31.

3 Busquets RM, Anto JM, Sunyer J, et al. Prevalence of asthma-related symptoms and bronchial responsiveness to exercise in children aged 13-14 years in Barcelona, Spain. Eur Respir F 1996;9:2094-8.

4 Haby MM, Anderson SD, Peat JK, et al. An exercise challenge protocol for epidemiological studies of asthma in children: comparison with histamine challenge. Eur Respir $\mathcal{f}$ 1994;7:43-9.

5 Hansen HS, Hyldebrandt N, Nielsen JR, et al. Blood pressure distribution in a school-age population aged $8-10$ pressure distribution in a school-age population aged 8-10 641-6.

6 Hansen HS, Hyldebrandt N, Froberg K, et al. Blood pressure and physical fitness in a population of children: the Odense Schoolchild Study. F Human Hypertens 1990;4: 615-20.

7 Quanjer PH. Standardized lung function testing. Clin Respir Physiol 1983;19(Suppl 5):95.

8 Standardized lung function testing. Official statement of the European Respiratory Society. Eur Respir F Suppl 1993;16: $1-100$.

9 Sterk PJ, Fabbri LM, Quanjer PH, et al. Airway responsiveness. Standardized challenge testing with pharmacological, physical and sensitizing stimuli in adults. Report of Working Party on Standardization of Lung Function Tests, European Community for Steel and Coal. Official statement of the European Respiratory Society. Eur Respir $\mathcal{F}$ Suppl 1993;16:53-83.

10 Amelung PJ, Postma D, Panhuysen CI, et al. Susceptibility loci regulating total serum IgE levels, bronchial hyperresponsiveness, and clinical asthma map to chromosome 5q. Chest 1997;111(Suppl 6):77-8S

11 Wong ZY, Tsonis D, van Herwerden L, et al. Linkage analysis of bronchial hyperreactivity and atopy with chromosome 11q13. Electrophoresis 1997;18:1641-5.

12 Mortagy AK, Howell JB, Waters WE. Respiratory symptoms and bronchial reactivity: identification of a syndrome and its relation to asthma. BMF 1986;293:525-9.

13 Clark CJ. The role of physical training in asthma. Chest 1992;101(Suppl 5):293-8S.

14 Ninan TK, Russell G. Is exercise testing useful in a community based asthma survey? Thorax 1993;48:1218-21.

15 Sporik R, Chapman MD, Platts MT. House dust mite exposure as a cause of asthma (see comments). Clin Exp Allergy 1992;22:897-906.

16 Haby MM, Peat JK, Mellis CM, et al. An exercise challenge for epidemiological studies of childhood asthma: validity and repeatability. Eur Respir F 1995;8:729-36.

17 Anderson SD, Silverman M, Konig P, et al. Exerciseinduced asthma. Br f Dis Chest 1975;69:1-39.

$18 \mathrm{McF}$ adden ERJ. Exercise performance in the asthmatic. $\mathrm{Am}$ Rev Respir Dis 1984;129:S84-7

19 Bundgaard A, Schmidt A, Ingemann HT, et al. Exerciseinduced asthma after swimming and bicycle exercise. Eur $\mathcal{F}$ Respir Dis 1982;63:245-8.

20 Deal ECJ, McFadden ERJ, Ingram RHJ, et al. Airway responsiveness to cold air and hyperpnea in normal subjects and in those with hay fever and asthma. Am Rev Respir Dis 1980;121:621-8.

21 Bundgaard A, Ingemann HT, Schmidt A, et al. Exerciseinduced asthma after walking, running and cycling. Scand $\mathcal{F}$ Clin Lab Invest 1982;42:15-8.

22 Godfrey S, Springer C, Noviski N, et al. Exercise but not methacholine differentiates asthma from chronic lung methacholine differentiates asthma from

23 Kattan M, Keens TG, Mellis CM, et al. The response to exercise in normal and asthmatic children. $\mathcal{F}$ Pediatr 1978; 92:718-21.

24 Siersted HC, Hansen HS, Hansen NC, et al. Evaluation of peak expiratory flow variability in an adolescent population sample. The Odense Schoolchild Study. Am f Respir Crit Care Med 1994;149:598-603. 